\title{
Efficacy of Green Synthesis of Silver Nanoparticles using Flowers of Calendula Officinalis
}

\author{
J. CHIDAMBARAM ${ }^{1}$, K. SARITHA ${ }^{1}$, R. MAHESWARI ${ }^{1}$ and M. SYED MUZAMMIL ${ }^{2 *}$.
}

PG \& Research Department of Biochemistry, KMG College of Arts \& Science Gudiyattam, Vellore District, Tamilnadu, India

PG \& Research Department of Biochemistry, Islamiah College (Autonomous) Vaniyambadi, Tamilnadu, India

syed_bio2004@yahoo.co.in

Received 14 January 2014 / Accepted 24 January 2014

\begin{abstract}
In India over more than 6,000 plants are used in traditional, folklore and herbal medicine. The Indian system of medicine has identified 1500 medicinal plants of which 500 are commonly used. Calendula officinalis, commonly known as marigold belongs to the family Compositae. Green synthesis of silver nanoparticles by herbal plants is presently under high exploitation. Our study deals with the synthesis of silver nanoparticles by using the flower extract of Calendula officinalis. The synthesis of silver nanoparticles occurred under the exposure of the flower extract to $1 \mathrm{mM}$ silver nitrate aqueous solution. During this process the complete reduction of was observed nearly 48 hours of reaction at $30{ }^{\circ} \mathrm{C}$ under vigorous shaking conditions. The colour change was noted in the reaction mixture and observed during the process of incubation period, it may be due to the formation of the silver nanoparticles which are able to produce the colour in the reaction mixture may be due to their specific properties of surface Plasmon resonance. The formation of silver nanoparticles is made confirmed by FT-IR, UV-Visible Spectroscopy. These showed that the particles were capped with the biomolecular compounds like terpenoids, aminoacids, proteins, alkaloids and some reducing agents etc from the contents of the flower extract of Calendula officinalis. However, future studies are needed to investigate the other hidden effects exhibited by the plant in order to make the plant as a proficient herbal drug therapy.
\end{abstract}

Keywords: Calendula officinalis flower extract, Silver nitrate, FT-IR, UV-Visible Spectroscopy

\section{Introduction}

Calendula officinalis is an aromatic, erect, annual herb that grows up to $60 \mathrm{~cm}$ in height with angular and glandular stems, leaves 2.5-7.5 cm long, lower spathulate, entire, upper lanceolate with cordateamplexicaul base, flower-heads terminal, heterogamous, light yellow to deep orange, ray florets fertile, achenes 1.0-1.5 cm long, boat-shaped, faintly ribbed, indigenous to central, eastern and southern Europe, cultivated commonly in North America, Balkans, Eastern Europe, Germany and India. It is commonly known as Zergul (Hindi), African marigold, Calendula, Common Marigold, Garden Marigold, Marigold, Pot Marigold (English), Butterblume (German), Chin Chan Ts'ao (Chinese), Galbinele (Romanian) and Ringblomma (Swedish). 
Calendula officinalis possess potent anti-inflammatory, antitumour, antioxidant, antibacterial, anti-HIV, anti-ulcer, antigenotoxic, chemoprotective and antiseptic properties ${ }^{1}$, a large number of phytochemicals have been found in various parts of the plants that include calenduline and oleanolic acid glycosides, sterol glycosides, alpha-and beta-amyrin, taraxasterol, lupeol, brein, faradiol, arnidiol, erythrodiol, calenduladiol, coflodiol and manilladiol, oleanolic acid glycosides, sterol glycosides, alpha-and beta-amyrin, taraxasterol, Saturated hydrocarbons, vitamin C, mineral substances and polyphenols.

Here the advantage of using flowers for the synthesis of silver nano scaffold is that they are easily available, safe to handle and has possess a broad variability of metabolites that may aid in reduction process ${ }^{2}$. A number of plants are being currently investigated for their major role in the synthesis of nanoparticles. Silver nanoparticles with a size range of 2-20 nm have been synthesized. Nanoparticles of copper, cobalt, zinc, nickel have also been synthesized in plants Azadirachta indica (Neem), Medicago sativa (Alfalfa), Aloe vera ${ }^{3}$, Emblica officinalis (amla, Indian Gooseberry) and microorganisms has already been reported.

\section{Experimental}

All the fine chemicals were purchased from Sigma Chemical Co., USA. All other chemicals used were of Good quality and Analytical grade.

\section{Phytochemical analysis}

Test for carbohydrates

A small quantity of extract was dissolved separately in $5 \mathrm{~mL}$ of distilled water and filtered. The filtrate was tested to detect the presence of carbohydrates.

\section{Molisch's test}

To $2 \mathrm{~mL}$ of extract, $2 \mathrm{~mL}$ of Molisch's reagent was added. Then, $2 \mathrm{~mL}$ of concentrated sulphuric acid was added along the sides of the test tubes. Disappearance in color on the addition of excess solution indicated the presence of carbohydrates.

\section{Benedict's test}

To $0.5 \mathrm{~mL}$ of extract, $5 \mathrm{~mL}$ of Benedict's reagent was added. The mixture was then boiled for 5 minutes. Presence of a bluish green precipitate indicated the presence of carbohydrates.

\section{Test for Proteins and Amino acids}

\section{Ninhydrin test}

A small quantity extract solution was boiled with $0.2 \%$ solution of Ninhydrin. Purple color indicated the presence of free amino acids.

\section{Test for Phytosterols and Triterpenoids}

\section{Salkowski test}

To $2 \mathrm{~mL}$ of the extract, $1 \mathrm{~mL}$ of concentrated Sulphuric acid added. Chloroform was added along the sides of the test tube. A red color produced in the chloroform layer indicated the presence of Phytosterols or if it is yellow in color at the lower layer indicated the presence of triterpenoids.

\section{Zinc hydrochloride reduction test}

The extract was treated with mixture of zinc dust and concentrated hydrochloric acid. Red color indicated the presence of flavanoids. 


\section{Flavonoids}

$1 \mathrm{~mL}$ of extract was added to $10 \mathrm{~mL}$ of $95 \%$ ethanol and kept in boiling water bath for 15 minutes and after filtration mg ribbon were added along with 2-3 drops of $\mathrm{HCl}$.

\section{Steroids}

$1 \mathrm{~mL}$ of extract was extracted with methanol for 15 minutes and then Libermann Burchard reagent was added drop wise.

\section{Preparation of flower extract}

The Calendula officinalis flowers were collected from the nearby farmer's field, Tirupattur, Tamilnadu. In our experiment, the flowers of calendula officinalis were involved in the synthesis of silver nanoparticles.

About $25 \mathrm{~g}$ of calendula officinalis flowers were taken washed thoroughly with double deionized water and boiled it with $500 \mathrm{~mL}$ double distilled water at $60-80{ }^{\circ} \mathrm{C}$ for $10-15 \mathrm{~min}$ after that, the solution was filtered through nylon mesh cloth as well as Whatmann No.1 filter paper and stored it at $4{ }^{\circ} \mathrm{C}$ in a refrigerator for the further study.

Then $5 \mathrm{~mL}$ of the flower extract was taken in $100 \mathrm{~mL}$ of conical flask and $1 \mathrm{mM} \mathrm{AgNO}$ solution was added and kept in a shaker for nearly 48 hours and the colour change was noted and observed. The procedure was repeated thrice for nanoparticle synthesis process.

\section{Characterization}

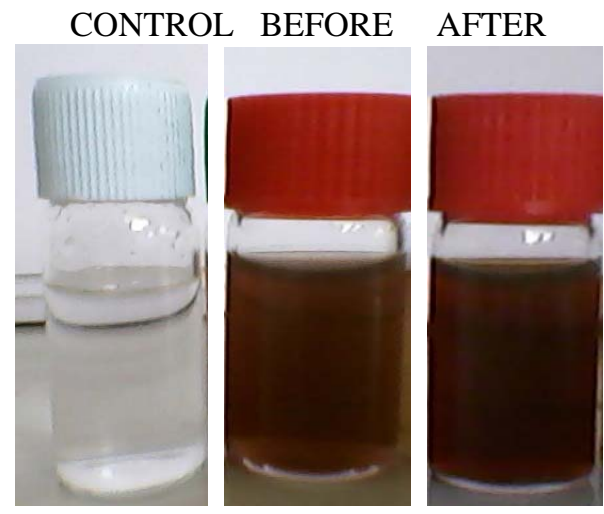

Figure 1. Preparation process of Ag-NPs.

\section{UV-Visible spectroscopy analysis}

The colour change in the reaction mixture (i e. Silver metal solution + flower extract) was recorded through the visual observations. The bioreduction process of silver ions in aqueous solution was monitored by periodic sampling of aliquots $(1 \mathrm{~mL})$ and subsequently measuring UV-Visible spectra of the solution. UV-Vis spectra of these samples were monitored as a function of time of reaction on Elico UV-Vis Spectrophotometer (model S3-159) operated at a resolution of $1 \mathrm{~nm}^{4}$.

\section{FT-IR Measurement}

FT-IR measurement of sample was performed using FT-IR spectrophotometer in a diffuse reflectance mode at a resolution of $4 \mathrm{~cm}^{-1}$ in $(\mathrm{KBr})$ potassium bromide pellets. 


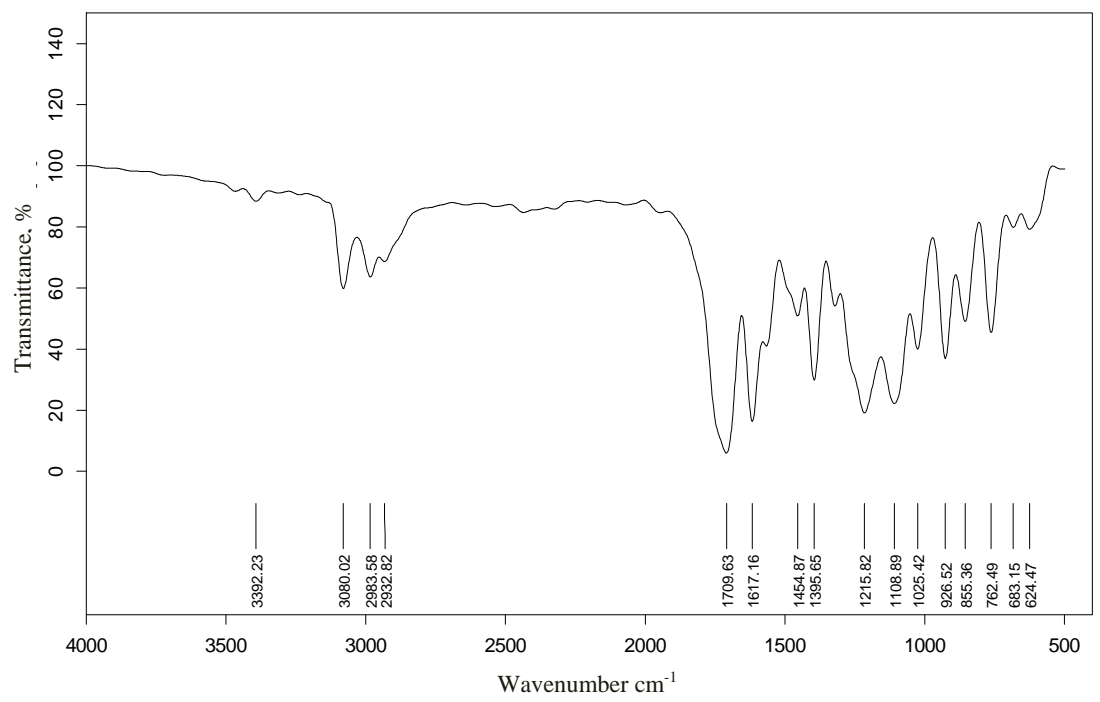

Figure 2. FT-IR Spectra of nanoparticles

\section{Results and Discussion}

UV-Vis spectroscopy analysis showed that the SPR absorbance band of silver nanoparticles synthesized using the flower extract of calendula officinalis flower extract centered at 440 460 nm and steadily increased in intensity as a function of time reaction without any shift in their peaks wave length, frequency, width of the SPR absorption depends on the size and shape of the metal nanoparticles as well as on the dielectric constant of the metal itself and the surrounding medium.

FT-IR analysis revealed that the carbonyl groups from the aminoacids residues and from the proteins extracts of the flower had a strong ability to bind metal indicating that the proteins could possibly form the layer covering the metal nanoparticles and prevent agglomeration and thereby stabilize the medium. Our experiment reveals that the biomolecules may possibly have dual formation and stabilization of the silver nanoparticles in the aqueous medium.

\section{Conclusion}

Aqueous extract of silver nitrate which, consist of silver ions exposed to the calendula officinalis flower extract for the synthesis of silver nanoparticles were made confirmed by the change of colour of the flower extract. More over further it was confirmed by UV-Vis Spectroscopy, FT-IR Spectra.

In our present study we found out that the flowers of calendula officinalis were good sources for the synthesis of silver nanoparticles and they may have more advantages and the process can be scaled of, in obtaining the nanoparticles size and its viability.

\section{Acknowledgement}

We are grateful to the faculty members of both the colleges, PG \& Research Department of Biochemistry, Principal, Islamiah College and K.M.G College, Principal, Secretary\& Correspondent, Islamiah College, General Secretary and VMES for their encouragement and support in carrying out the work. 


\section{References}

1. Preethi K C, Kuttan G and Kuttan R, Pharmaceutical Biol., 2006, 44(9), 691-697; DOI:10.1080/13880200601009149

2. Baker C, Pradhan A, Pakstis L, Pochan D J and Shah S I, J Nanosci Nanotechnol., 2005, 5, 224-249.

3. Chandran P K and Kutton R, J Clin Biochem Nutr., 2008, 43(2), 58-64; DOI:10.3164/jcbn.2008043

4. Udayasoorian K, Vinoth Kumar and Jayabalakrishnan R M, J Med Aromat Plant Sci, 2011, 33(2), 128-132.

5. Shabana S, Syed Muzammil M and Parsana S, Int J Herbal Med., 2013, 1(2), 169-174. 